\title{
Wildlife Numbers May Be Improved By Team Work between Homo sapiens and Big Cats
}

\author{
Kaufui V Wong* \\ Coral Gables, USA \\ Submission: November 16, 2016; Published: December 19, 2016 \\ *Corresponding author: Kaufui V Wong, University of Miami, Coral Gables, Florida, USA
}

\begin{abstract}
The World Wildlife Fund and the Zoological Society of London have sponsored a study which has concluded in October 2016, that the population of wildlife has decreased by $58 \%$ worldwide in the last forty years. This problem needs to be addressed. The attitude of Homo sapiens towards big carnivores has started to change about three decades ago around the Gir Protected Area (Gir PA), India. The people around the Gir PA in southern Gujarat, has possibly shown the way of how to collaborate with resident local lion pride to control deer and antelope populations in their area. The deer and antelope are agricultural pests and come frequently at night to graze on the choice vegetative tid-bits. Meanwhile, in Bangladesh, the people of the Ganges delta area collect wild honey from the wild bees that harvest their ware among the mangrove forests. The resident tiger(s) are left to control other poachers who try to steal the wild honey from the locals.

The locals go in groups so as not to be overpowered / killed by the dominant tiger in the area. Local involvement by the residents is essential. The common wisdom to be drawn is that a high level of collaboration is possible between man and the big cats. Understanding and forgiveness seem to be the key qualities of Homo sapiens essential for collaboration to succeed with the big cats in their natural habitat. The sustainable future of an apex predator species may hinge on this philosophy being replicated wherever there seems to be a current problem around the world.
\end{abstract}

Keywords: Homo sapiens; Asian lion (Panthera leo persica); Asian leopard (Panthera pardus); Bengal tiger (Panthera tigris tigris); Phobia

\section{Introduction}

The Zoological Society of London and the World Wildlife Fund have funded a study which has concluded in late October 2016, that the worldwide wildlife numbers have dropped by $58 \%$ in the last four decades. This paper presents one possible response to reverse this upsetting trend. In the past, the behavior of man (Homo sapiens) towards the big cats in India was in general contentious $[1,2]$. This is to be expected, seeing how this adjective would apply rather well to most areas around the world. One dominating reason would be the competition for resources and the protection of agricultural resources. These factors have obviously become more acute with yearly global population rise, global climate change and sea-level rise. However, the people's actions involved in the state of Gujarat, India, have started to change in the recent past three decades, coupled with laws passed in India to protect animal rights in the Preserved Areas (Pa's). This paper looks principally at two educational movies made about two different areas in South Asia, one in India and the other in Bangladesh, which echo a common trait. This trait is that collaboration between wild big cats and Homo sapiens is possible for mutual good, and promises a sustainable future in both areas.
A literature search about 'big cats' and 'South Asia' brought up the following sampling of related scholarly works. A concept paper has been put forward for living with the leopard (Panthera pardus) [3]. The number of big cats per unit area is a function of the number of prey in that same area $[4,5]$. As an interesting fact, the domestic dog is an essential item in the nutritional regimen of the leopard [6-8]. One of the suggested actions in [3] is the control of fertility among the leopards [9]. There does not seem to be a hypothesis/thesis paper based on a high level of collaboration between Homo sapiens and wild big cats, as is proposed in the current work.

\section{Theoretical and Experimental Methodology}

The current work and deductions are based largely on two educational movies, which were reviewed and broadcast in a South Floridian educational channel in the United States of America. These movies were done independently of each other, and had different objectives other than the deductions obtained by the current author. The current work is not a regular research paper, but more a commentary of the author about what he observed from a couple of movies regarding the 
status or relationship between Homo sapiens and the big cats in two different parts of South Asia, and his observations and deductions.

For the benefit of those who might want to pursue further scientific evidence of the deductions made here, an outline of the theory and experimental methodology is now presented. Much of the theoretical methodology is obtainable in the published literature, of which many are in the reference list of this article. The experimental methodology is the common method used in both educational movies cited. Like many modern biological studies, video-recording of real-time happenings of the big cats as they strive to survive in the midst of human encroachment, is key. The current article is written without financial backing. Obviously, scientific research to establish the deductions of the current work need research funding, and scientists willing to carry out the field studies in the respective sites. Animal and environmental research being what they are, the conditions prevalent at any specific site is unique, and have to be studied and documented accordingly.

\section{Gujarat and the Asian Lion 'Nature}

The Wondering Lions of India' [10] is an hour-long movie regarding the Asian lion (Panthera leo persica) in the Gir Protected Area (Gir PA) of the Gujarat State in India, and the nearby areas outside the PA. The movie introduces the superior intelligence of the lions by stating that of all the big cats, the lion has the largest pre-frontal cortex in size. This fact gives a predisposition to the lions in making better decisions. The lions are shown carrying out a 'chase-and-catch' strategy to capture their prey, an example being the sambar deer (Rusa unicolor). There are lionesses that act as the chasers which chase the herd of deer and break them up into smaller groups of three or less, and there is usually one lioness that plays the catcher which makes the 'kill' of a single prey. This single unfortunate deer had previously been identified to be the target, by the manner it was separated from the rest of the herd.

The effectiveness of this serious lion strategy needs to be observed to be fully appreciated. One can even liken the strategy to one used successfully by Homo sapiens in a highly competitive American football game. The movie [10] goes on to show a random and seldom killing of a village ox by a lone lion. The villagers are shown approaching slowly but surely, to seemingly close quarters to view the lone lion feeding on the carcass of their ox. In fact, the villagers when interviewed stated that they are very happy to sight a lion feeding on one of their animals. The villagers see it as a rare payment to the local resident lions as a whole, for their service to their community. There is no retribution of lions that kill cattle once in a while. (This is in a country where the majority Hindus considers the cow to be a holy animal, and do not slaughter cows for food.) In good film tradition, the viewer is left wondering what this 'service' could be.
There is a warning that children have to be aware of possible attack by the resident lions of the area around the village. Adults, even if only a couple of them, need not worry about the resident lions. The movie [10] then tells the story of how three young lions do not attempt to bother the domestic dogs, especially when they are six or seven of them barking at the lions as they saunter by the village. The bottom line is that the villagers are in general, safe with the resident lions. Reference [11] is the seminal work by Divyabhanusinh about the history of the Asian lion in South Asia. By the mid-19th century, only twenty wild lions were counted in the state of Gujarat, India [11]. Then, the lions received protection from a local prince via decree. Divyabhanusinh [11] goes through in historical detail about how the situation for Asian lions morphed into what it is today in South Asia.

Even Divyabhanusinh refrained from going into the unknown territory that is the 'big cat' situation in Gujarat today, with the complex problem of climate change, human pressure in and around the PA, etc. It will be pretentious and too ambitious for the current work to address these same issues. In a related topic, reference [12] is the recent work of Rangarajan and others with regards conservation of elephants in India. Reference [13] is a 2007 publication about the conservation of the Asian lion in another area of India, Madhya Pradesh. At the present time, a decade and a half into the $21^{\text {st }}$ century, there are about 500 wild lions in Gujarat. This top-ranked predator is supported by a 10fold increase in spotted deer, a 5-fold increase in sambar, and a 3-fold increase in Nilgai (Boselaphus tragocamelus) [10]. Just from the evidence, there must be something right going on in the area under discussion.

The stories narrated in the movie include the one that the dry Gir forests (24 inches of rain a year [10]) is a tropical dry forest, with lots of dry, dead foliage on the floor of the forest. This dry foliage makes it difficult for the lions to stalk prey successfully in the forests. There is no dry dead leaves in the villagers' cultivated land. The gray langurs (Semnopithecus) forage together with the spotted deer in the forests. These monkeys provide an early warning system from the tree tops to the spotted deers, thus spoiling any kill strategies of the lions in the forests. The humans discourage the monkeys from encroaching on their land. For the reasons recounted above about the difficulty in hunting, many lions have moved out of the Gir forests in southern Gujarat. The wheat and sesame seed plants of the southern Gujarati villagers are irresistible to the deer and antelope, which often come at night to raid.

The farmers watching their fields see the deer easily using a flashlight and the 'deer in the headlights' phenomenon because the deer's eyes reflect brightly the flashlight. By calling out, the farmers bring the attention of the resident lions to the night invaders of their crops. The herd of deer can smell the lions, but cannot see them in star-light. There is good stalking for the lions in the cultivated land since there is no dry foliage or sticks on the 
ground. The pack of resident lionesses can carry out their chaseand-catch strategy to completion and fruition. The cry of the distressed spotted deer breaks the night silence, and it signals for all the lions in the team to come for their deserved meal. By this symbiotic relationship or collaboration between the lion and humans, the southern Gujarati villagers have demonstrated that humans and the big cat can live alongside each other.

The occasional kill of domestic cattle is considered rare payment for consistent service of crop protection provided by the resident lions. Even when a human is killed but the big cat did not linger and partake of the human corpse, the lioness is forgiven and her human victim blamed for invading 'her territory', probably when vulnerable cubs were involved.

\section{Delta Area of Bangladesh and the Bengal Tiger}

'Nature: Tigers of the Sundarbans' [14] is an hour-long movie regarding the Bengal tiger (Panthera tigris tigris) in the mangrove-forested delta region of Bangladesh. The Sundarban is the largest area of mangrove forest in the world. The work of Loe and Roskaf [15] is a review of the major carnivores and human safety. In it, it was concluded that it was not possible to predict why and when the big cats even attack humans in a specific area, e.g. the Sundarban. This conclusion came after review of papers focused on the tigers of the Sundarban, including $[16,17]$. In Bangladesh, the people of the Sundarban, collect wild honey (alongside fishing and other activities) from the wild bees that build their hives among the mangrove forests. The good prices of the honey provide a good incentive. The search for such hives is long and arduous and could take several days. The resident tiger(s) are left to control other poachers who try to steal the wild honey from the locals [14]. Apparently, the unwary poachers have entered the villagers' territory of foraging, alone and unaccompanied.

The locals go in groups so as not to be overpowered / killed by the dominant tiger in the area. They also make a lot of collective noise to let the tiger know that he is up against many persons rather than an uninformed individual. A single human killed by being careless and wandering alone into the mangrovecovered swamp is forgiven by the villagers [14] on the grounds that it was 'not the tiger's fault'. The brother-in-law of the victim has forgiven the culprit tiger, and not gone after it with a deadly weapon or a group of friends with weapons. Apparently, the victim had no brothers, and women (victim's sister(s)) are not expected to be the lead in the family on decisions to take action or not regarding an insult/injury to the family. Annu Jalais has done pioneering anthropological work on the Bengal delta, now divided politically between India and Bangladesh [18,19]. He points out the differences between the 'cosmopolitan' view of the Bengal tiger and that of the people who have to share the land with the tigers.

The lesson learned is that there can be a working relationship between Homo sapiens and the Panthera tigris tigris. The sustainable future of a pinnacle predator species may depend on this philosophy and the concomitant actions being replicated throughout the world. These animals are wild. The occasional kill of a human is a very good hint. However, the forgiveness of the humans is essential for this practice to work. A revenge killing would just cause the confrontation between humans and the next tiger to claim the territory to continue. Cooperation and participation of the local residents are critical for such planned actions to succeed.

At this point, it is appropriate to recognize the actions of Jim Corbett, who hunted man-eating tigers and leopards in certain Indian states during his young days [20]. Apparently, he was just copying the long history of Indian princely hunting. Later on in life, he radically changed his views, and called for the government of the Indian states to protect the very same big cats he hunted previously. 'Man Eating Tigers of the Sundarbans' [21] is a British Broadcasting Corporation (BBC) movie that recounts of the man-eating Bengal tigers in the Sundarbans, from a slightly different perspective. The reason proffered for the tiger's developed taste for human flesh is from clearing up the corpses after the ravages of a typhoon, which is frequent in the region, another possibility in that the corpses are washed downstream to the Sundarbans by the floodwaters of the rivers.

In [21], foreign wildlife professionals try to train a pack of domestic dogs to help the villagers defend themselves against the tigers. Apparently, domestic dogs are not allowed in the Sundarbans, a World Heritage site. It is hoped that this rule will be relaxed in the future. It is interesting that this fact ties back to the findings that the dog is a vital item in the diet of the leopard, a big cat with somewhat different hunting characteristics from the lion or tiger [6-8]. There are a number of YouTube videos which tell of stories of the retaliation of Homo sapiens against the big cats for the kills the big cats have made, especially of humans. These videos collectively form the evidence that the hypothesis/thesis proffered by the current work is not going to be met with easy acceptance, and indirectly that the proposition is indeed novel. Reference [22] is a recent study about the whole region, looking at the economics of the people living in this part of Bangladesh. The Bengal tiger does not feature in [22]. Apparently, the researchers found that the economics of the region did not warrant the consideration of the tiger as a significant contributing factor.

\section{Discussion and Conclusion}

The attitude of humans towards big carnivores has typically been contentious or total separation of territory. A novel hypothesis/thesis has been derived, based on audio-visual data available from the media. The motivation has been the alarming drop in world wildlife numbers. This paper has recounted the stories mainly from two separate educational movies shown on American television in 2016, and a BBC movie. I also refer to a bunch of YouTube videos, too numerous to be cited. Considering how easily these YouTube videos can be made and published 
online, they are also unsuitable for mention in scholarly academic articles. The people around the Gir PA in southern Gujarat, has revealed one way of how to collaborate with resident local lion pride to control deer and antelope populations which are pests to their agricultural crops.

In Bangladesh, the people of the Ganges delta area collect wild honey among the mangrove forests. The resident tiger(s) are left to control other poachers who try to steal the wild honey from the locals. The piece of wisdom to be obtained from these narratives is that cooperation is possible between man and the big cats (Asian lion and Bengal tiger). The sustainable future of a pinnacle predator species may depend on this philosophy and the concomitant actions being replicated throughout the world. However, the forgiveness of the humans is essential for the practices presented to work. There can be no revenge-killing by the humans for rare incidences when a domestic animal is killed for food, and even when the rare human is killed (not for food). The participation of the local people is critical.

This is of course an idealized proposition, and no attempt is made in this short communication to address the real difficult factors that could arise differently in the various parts of the world. This paper has strived to show the limited positive evidence already experienced in two parts of South Asia. A side fact that might come out of this work is that the working relationships between wild animals and humans may be developed over time as had already been done in previous and current generations in the circuses, lumber yards of South and Southeast Asia, the aquariums and suchlike facilities in the western world. The wildness of the working/performing animals should never be forgotten, and their instinctive needs for mates and sex (seasonal, unlike humans) should not be ignored. The actions of certain rogue animals e.g. rogue elephant, should not spoil it for all other animals.

The sustainable future for any top-predator species depends on the preservation of its habitat and a workable relationship between them and humans. This experiential deduction comes out of research and publishing academic papers on related subject areas [23]. Certain topics such as the current one and that published in [24], does not lend themselves to the easy design of a strict scientific study that would get the nod and research funding from the establishment. The increasing human population and the increasing top-predator species population in this World do not lead to a simple situation without compromise and wise thinking on the part of Homo sapiens. The current paper can also be perceived as a partial response to the darker picture painted by reference [25], entitled 'The human-felid conflict'.

The two 'advanced' methods presented in the current work, is considered more equitable to the big cats and thus more 'advanced' than taming the big cats, as was done in Thailand [26]. In the Tiger temple thailand [26], tourists were invited to pet the young tigers, as well as the adult tigers. As of April 2015, there were 167 tigers in the sanctuary, which was run by
Buddhist monks. As of June 4, 2016, the monks are no longer in charge of the tigers [27]. The tigers are in the custody of the Thai Department of National Parks, and kept in a sanctuary. The tigers were basically tame, because they were fed and cared for by the monks, and adult tigers have been trained. (The pricing system was based on human psychology. Baby tigers were more expensive to pet than adult ones, since they are safer to handle. The peaceful and tranquil sanctuary was a place for humans with a phobia of big cats to try to overcome some aspects of their fear).

The current criminal case against some of the custodial monks is based on evidences of tiger parts for sale, sourcing to the Buddhist temple. This controversial 'collaboration' case is nonetheless considered to be at a lower level than that proposed in the current work. Humans can and should reach for the higher level of collaboration between us and the big cats, wherever it is expeditious to do so. Understanding combined with forgiveness seems to be the two important qualities required of Homo sapiens to succeed.

\section{References}

1. Vijayan S, Pati BP (2002) Impact of changing cropping patterns on mananimal conflicts around Gir Protected Area with specific reference to Talala Sub-District, Gujarat, India. Population and environment 23(6): 541-559.

2. Pati BP, Hanif BM, Pathak BJ (2002) Rescue and Health Status of Big Carnivores in and around Gir Protected Area (Gir Pa), Gujarat. Indian forester 128(10): 1133-1144.

3. Alam MS, Kumar S (2015) Investigating Human-Leopard Conflict In and Around Gir Protected Areas. Concept Paper.

4. Carbone C, Gittleman JL (2002) A common rule for the scaling of carnivore density. Science 295(5563): 2273-2276.

5. K Ullas Karanth, James D Nichols, Narayanarao Samba Kumar, James E Hines, James E Hines (2004) Tigers and their prey: Predicting carnivore densities from preyabundance. Proceedings of the National Academy of Sciences 101(14): 4855-4858.

6. Mukherjee S, Mishra C (2001) Predation by leopard Panthera pardus in Majhatal Harsang Wildlife Sanctuary, W. Himalayas. Journal of the Bombay Natural History Society 98: 267-268.

7. Edgaonkar AJ and Chellam R (1998) A preliminary study on the ecology of the leopard, Panthera pardus fusca in the Sanjay Gandhi National Park, Maharastra. Wildlife Institute of India, Dehradun, India, p 39.

8. Athreya VR, Thakur SS, Chaudhuri S and Belsare AV (2004) A study of the man-leopard conflict in Junnar Forest Division, Pune District, Maharastra. Maharastra State Forest Department and the Wildlife Protection Society of India, New Delhi.

9. Tuyttens FAM and Macdonald DW (1998) Animal Welfare, Universities Federation for Animal Welfare 7(4): 339-364.

10. "Nature: The Wandering Lions of India," Educational T.V., 2-3 p.m., 4/24/16, WLRN17TV.org, Channel 17.1, South Florida, USA.

11. Divyabhanusinh (2005) The Story of Asia's Lions. Mumbai: Marg Publications, $259 \mathrm{pp}$.

12. Rangarajan M, Desai A, Sukumar R, Easa PS, Menon V, et al. (2010) Gajah: Securing the Future for Elephants in India. The Report of the Elephant Task Force. New Delhi: Ministry of Environment \& Forests, India. 
13. Johnsingh AJ, Goyal SP, Qureshi Q (2007) Preparations for the reintroduction of Asiatic lion Panthera leo persica into Kuno Wildlife Sanctuary, Madhya Pradesh, India. Oryx 41(01): 93-96.

14. "Nature: Tigers of the Sundarbans," Educational T.V., WLRN17TV.org, Channel 17.1, South Florida, USA.

15. Löe J, Röskaft E (2004) Large carnivores and human safety: a review. AMBIO 33(6): 283-288.

16. Hendrich Hurbert (1975) The status of the tiger (Panthera tigris) (Linne, 1758) in the Sundarbans Mangrove Forest. Saeugetierkundliche Mitteilungen 23(3): 161-199.

17. Jackson P (1985) Man-eaters. International Wildlife 15(6): 4-11.

18. Jalais Annu (2008) Unmasking the cosmopolitan tiger. Nature and Culture 3(1): 25-40.

19. Jalais A (2014) Forest of tigers: People, politics and environment in the Sundarbans. Routledge.

20. Wikipedia, Jim Corbett.
21. BBC, Man Eating Tigers of the Sundarbans.

22. Hossain MS, Dearing JA, Rahman MM, Salehin M (2015) Recent changes in ecosystem services and human well-being in the Bangladesh coastal zone. Regional Environmental Change 16(2): 429-443.

23. Wong KV (2015) Perspective about the Management, Preservation and Conservation of Apex Predator Species: Economic Potential of Culling in Wildlife Management Areas. J of Basic and App. Research International, IK Press, 14(4).

24. Kau-Fui Vincent Wong, Ramarathnam Narasimhan, Rajnish Kashyap, Jianlin Fu (1994) Medical waste characterization. Journal of environmental health 57(1): 19.

25. Chloe Inskip, Alexandra Zimmermann (2009) Human-felid conflict: a review of patterns and priorities worldwide. Oryx 43(01): 18-34.

26. Tiger Temple Thailand.

27. Ansari A and Olarn K (2016) All Tigers removed from Thailand 'Tiger Temple'. CNN.com.

Your next submission with JuniperPublishers will reach you the below assets

- Quality Editorial service

- Swift Peer Review

- Reprints availability

- E-prints Service

- Manuscript Podcast for convenient understanding

- Global attainment for your research

- Manuscript accessibility in different formats (Pdf, E-pub, Full Text, Audio)

- Unceasing customer service

Track the below URL for one-step submission http://juniperpublishers.com/online-submission.php 